\title{
Physiques in Migrant Peasant Worker’s Children by Comparison with Rural and Urban Children in Shanghai, China
}

\author{
Jin-Kui Lu ${ }^{1 *}$, Xiao-Jian Yin ${ }^{2}$, Takemasa Watanabe ${ }^{1}$, Yan-Min Lin ${ }^{3}$, Toyoho Tanaka ${ }^{1}$ \\ ${ }^{1}$ School of Health and Sport Sciences, Chukyo University, 101 Tokodachi, Kaizu-cho, Toyota, \\ Aichi, Japan \\ ${ }^{2}$ Key Laboratory of Adolescent Health Assessment and Exercise Intervention, Ministry of Education, School of \\ Physical Education and Health, East China Normal University, Shanghai, China \\ ${ }^{3}$ Department of Physical Education, Lvliang College, Lvliang, China \\ Email: *lujinkui2013@126.com
}

Received November $26^{\text {th }}$, 2013; revised December $26^{\text {th }}, 2013$; accepted January $4^{\text {th }}, 2014$

\begin{abstract}
Copyright $\odot 2014$ Jin-Kui Lu et al. This is an open access article distributed under the Creative Commons Attribution License, which permits unrestricted use, distribution, and reproduction in any medium, provided the original work is properly cited. In accordance of the Creative Commons Attribution License all Copyrights (c) 2014 are reserved for SCIRP and the owner of the intellectual property Jin-Kui Lu et al. All Copyright (C) 2014 are guarded by law and by SCIRP as a guardian.
\end{abstract}

Background: a few studies have been conducted which describe health status of Migrant Peasant Worker's children. However, there are no studies which compare physiques of MPW's children with those of rural children and urban children. Also, few studies have been done on physiques of MPW's children as it relates to socioeconomic factors in China. Methods: We examined across-sectional study of 2457 children from Shanghai and Wuhu city in 2011. First, we compared the differences of physiques among three groups by ANOVA. Second, ANCOVA were applied to analyze the associations between the physiques and socioeconomic factors by taking physiques as dependent variables. The independent variables included socioeconomic factors such as the parental occupation, the parental education and family monthly income. Third, ANCOVA were used to assess differences in physiques among the three groups by adjusting socioeconomic factors. Results: There were significant differences in all physical indexes, no matter they were boys and girls $(\mathrm{P}<.001)$. Children's physiques of MPW were smaller than those of children of Citizen in Shanghai City. Among all ages, regardless of gender, Children's physiques of MPW were bigger than those of children of rural resident. In both boys and girls all indexes displayed statistically significant associations with parental occupations $(\mathrm{P}<.001)$. There were strong associations between parental education and all physical indexes $(\mathrm{P}<.001)$. Family monthly income was found to be significantly associated with children's physiques $(\mathrm{P}<.001)$. In both boys and girls, there were strong associations between physique and group in all indexes $(\mathrm{P}<.001)$, but physiques hardly had any associations with socioeconomic factors. Conclusions: We find that physiques of MPW's children were smaller than those of children of citizen in Shanghai City, and physiques of MPW's children were bigger than those of children of rural resident. There are strong associations between physiques and socioeconomic factors.

Keywords: Migrant Peasant Worker; Children; Physiques; Socioeconomic Factors; Group

\section{Introduction}

With the rapid urbanization in China, it was extremely obvious that there was shortage of labor in southeast coastal cities. Since the economic reform and Opening-Up Policy in China, the spare labor force was transferring from rural areas to cities, and the population of the labor has consistently increased. The term "Migrant Peasant Worker" (MPW), referred to those who migrate from rural areas to urban areas seeking employment opportunities. Most MPWs children accompanied their parents to the cities. At the end of 2009, the number of MPWs has reached over 145 millions (State Statistic Bureau, 2009). Moreover, the number of MPWs' children less than 14 years old was estimated at 15 millions, and about 380 thousand MPWs' children were in Shanghai City in 2005 (Xiong, 2010).

Chinese government has classified every Chinese citizen as

${ }^{*}$ Corresponding author. either "rural register" or "urban register" as a means of categorizing household registration. This system is known as "Hukou". Newborn have to be registered in the area of parental registration. Citizens can only receive government benefits within the district of their household registration. Moreover, any reformations to Hukou are restricted because there are significant differences in government benefits from local governments in rural Hukou and urban Hukou. Urban citizens enjoy access to state-subsidies such as food allowance, life employment, medical insurance, housing, social security and pensions. Those who were designated as rural Hukou are not entitled to these citysubsidies (Solinger, 1999). MPWs have no access to services from local states due to their rural Hukou, and their children are unable to attend state schools in cities. They usually can not afford expensive private schools, so they are forced to attend schools in very poor condition. Hence, the MPW's children are at higher risk of suffering from poor health than the children of 
urban Hukou. On the contrary, since the migration from rural area to urban area has increased MPWs family income (Alaimo, Olson, Frongillo, Briefel, 2001), they are in a better position to provide for their children. Their increased income enables more MPWs to purchase medical insurance for their children, which ensures adequate medical care. From this aspect, migration has a favorable impact on their children's health (Belsky, Bell, Bradley, et al., 2007; Black, Morris, Smith, Townsend, Whitehead, 1988; Bornstein, Hahn, Suwalsky, \& Haynes, 2003).

Many studies have reported health issues of MPWs and their children. MPWs were generally found to be in poor health, having a comparatively high prevalence of illness (Chen et al., 2010; Ma, 2008) compared to children who are citizen of cities, MPWs' children are underweight and undernourished compared to children of citizen in cities (Bradley \& Kelleher, 1992; Chen et al., 2010; Chen et al., 2006). Zhang reported that MPWs' children have higher prevalence of underweight, anemia and dental caries than children of citizens in Shanghai city (Zhang et al., 2005). However, this study was based on physical measurement only in MPWs' children. The data for children of citizens in Shanghai city was used from a former Yearly Health Check Record. Yin showed that MPWs' children have lower weight than children of citizens in Shanghai city, but this report did not refer to the socioeconomic factors (Yin et al., 2011). Li reported that the growth and development parameters (height, body weight, chest circumference, vital capacity, body mass index)of children from MPWs were much lower than that of urban children, but the sample size of the study was small (625 subjects including 2 groups), and the socioeconomic factors were not mentioned(Li, Zhou, 2011). Yan showed that MPWs' children have bigger physique than children living in rural areas from which MPWs' children come after observing adjustment by family income. The author explained the results in the following way. Since the migration improved family income, MPW's wages afforded them a higher quality of consumer goods and lifestyle than that was available to most children living in rural areas, but parental occupation and education were not mentioned (Yan, 2005).

There are many studies on the health problems of immigrant children in other countries. Immigrant children can be divided into international immigrant children and internal migration children. International immigrant is defined as immigrants who move from one country to other country, and internal migration is called migration from one region to another region in the same country. We believe that Chinese MPWs exhibit the same characteristics as international immigrations as well as internal migrations. On the one hand, MPWs have no "urban Hukou" in cities and in the same way international immigrants have no local nationality. On the other hand, Chinese MPWs are from rural areas to urban areas in China. They are similar to internal migration, because both of them speak the same language and have similar lifestyle.

The international immigrant children with low socioeconomic status (Bogin, Smith, Orden, Varela Silva, Loucky, 2002; Hernandez, 2004) and limited health care access (Casey, Szeto, Lensing, Bogle, \& Weber, 2001; Desai \& Alva, 1998; Dittus, Hillers, \& Beerman, 1995) were at higher risk of poor health status than native-born children. The immigrant children have been identified as having an array of poor health status and these include: growth retardation (Geltman, Radin, Zhang, Cochran, \& Meyers, 2001; Huang, Stella et al., 2006) obesity
(Fredriks, Buuren, Jeurissen, et al., 2004; Geltman, Radin, Zhang, Cochran, Meyers, 2001; Guarnaccia, Lopez, 1998), and mental health problems (Guarnaccia, Lopez, 1998; Hu, 2004). For children of internal migration, some studies have showed that they were stunted and underweight due to their bad lifestyles (Glew, Brock et al., 2004; Slesinger, Christenson, Cautley, 1986). Slesinger reported that the migrant farmers' children are at substantially greater risk of health problems and earlier mortality than the urban children in Wisconsin, since they lack access to regular physical checkup (Slesinger, Christenson, Cautley, 1986). Glew showed that west Africa Fulani immigrant children and adolescents (5 - 18 years old) have smaller physiques than Nigerian children in northern Nigeria due to their poor lifestyles (Glew, Brock, et al., 2004). However, some studies have shown that immigration are likely to have earlier onset of puberty ,improved physical status and reduction of the prevalence of stunting (Bogin, Smith et al., 2002; Garnier, Ndiaye, Benefice, 2003). Bogin et al. showed that Maya immigrant children living in Florida in USA are taller and have longer leg than their counterparts living in Guatemala (Bogin, Smith, et al. (2002) Garnier reported that immigration from rural areas to Dakar in Senegal resulted in Senegalese children having an earlier onset of puberty and an improvement of nutritional status (higher BMI, fat mass index and midarm circumference) but without catch-up in growth (Garnier, Ndiaye, Benefice, 2003). There are almost no reports that internal migrant children's physiques and health status have improved by their immigration in China.

\section{Purpose}

In China, as previously described, there are many studies on the health of MPW's children. However, there are no studies which compared physiques of MPW's children with those of rural children and urban children at the same time and few studies on physiques of MPW's children which take socioeconomic factors into consideration. The present study is aimed at evaluating physiques of MPW's children as they with rural and urban children while taking socioeconomic factors into account. We hypothesize that MPW's children have smaller physiques than urban children and MPW's children have bigger physiques than rural children after the adjustment by socioeconomic factors.

\section{Methods}

\section{Study Design}

This study was a cross-sectional survey of children aged 7 12 years in Shanghai city and Anhui province, China. The research plan was approved by the Ethical Committee of Graduate School of Health and Sport Sciences in Chukyo University.

\section{Study Area}

The study areas were located in Shanghai city and Wuhu city in Anhui province. The province is the origin of the greatest number of MPWs in Shanghai city

(http://www.stats.gov.cn/tjfx/jdfx/t20110428_402722253.htm.2 011/11/24). Furthermore, the latitude and temperature in Wuhu city are almost the same as Shanghai city (annual average temperature: Shanghai $15.8^{\circ} \mathrm{C}$, Wuhu city $15.9^{\circ} \mathrm{C}$ ). Anhui province 
is located in Eastern China, across the basins of the Yangtze River and the Huai River. The capital of the province is Hefei. Wuhu city locates in $143 \mathrm{~km}$ southeast of the Hefei city. The city covers $3317 \mathrm{~km}^{2}$ and contains a total population of about $2,307,000$ people. The majority of the population lives in rural area. It is an agricultural district which heavily exports its labor force. $^{29}$ Shanghai is located at the mouth of Yangtze River Delta in the middle portion of the Chinese coast. Shanghai city covers $6340.5 \mathrm{~km}^{2}$ and contains a total population of about $23,470,000$ people. It is a major financial center and the busiest hub in China

(http://en.wikipedia.org/wiki/Shanghai. 2011/12/02). (Figure 1)

\section{Subjects}

The subjects included two urban groups in Shanghai City and one rural group in Anhui province. Each group consisted of school children from two primary schools. Of two urban groups, one group was MPW's children in 2 special primary schools

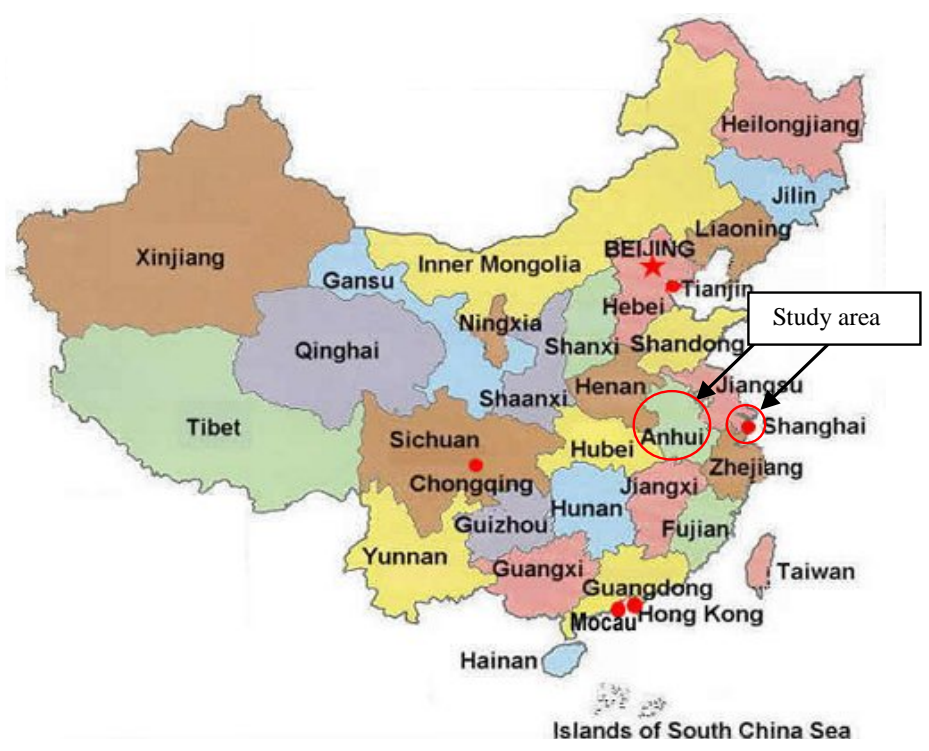

(a) founded by MPWs themselves. One of two schools is located in urban areas and another one is in a suburb of Shanghai. The other group is made up of children of Shanghai citizens. The children are from 2 state primary schools. One is located in an urban areas and the other in the suburbs. For the rural group, 2 state primary schools were selected from rural areas in Wuhu city. One lies in rural mountain district and the other is in rural plain district. The original cohort consisted of 4132 subjects, all children from 6 primary schools. Among them, 964 were not measured due to their absence during physical measurement session, and 592 did not complete questionnaires. After physical measurement, 119 were excluded, because 95 were not in the required age range of 7 to 12, and 24 were from ethnic minority (Figure 2). We defined children of rural resident as group 1, MPW's children as group 2 and children of Citizen in Shanghai City as group 3. Finally, there were 748children in group 1, 914 in group 2 and 795 in group 3 for the analysis (Table 1).

Figure 1.

Maps showing (a) location of two study areas in China and (b) location of Wuhu City in Anhui province.

Table 1.

Distribution of the demographic characteristics of the three group children.

\begin{tabular}{cccc}
\hline & Rural resident & Migrant peasant worker & Citizen in Shanghai city \\
\cline { 2 - 4 } & $\mathrm{N}(\%)$ & $\mathrm{N}(\%)$ & $\mathrm{N}(\%)$ \\
\hline All & $748(100)$ & $914(100)$ & $795(100)$ \\
Gender & & & $403(50.7)$ \\
Male & $438(58.6)$ & $557(60.9)$ & $392(49.3)$ \\
Female & $310(41.4)$ & $357(39.1)$ & $100(12.6)$ \\
Age (years) & & & $115(14.5)$ \\
7 & $74(9.9)$ & $107(11.7)$ & $167(21.0)$ \\
8 & $97(13.0)$ & $182(19.9)$ & $206(25.9)$ \\
9 & $120(16.0)$ & $204(22.3)$ & $149(18.7)$ \\
10 & $152(20.3)$ & $162(17.7)$ & $58(7.30)$ \\
\hline
\end{tabular}




\section{All students in 6 primary schools $(\mathrm{N}=4132)$}

Group $1(\mathrm{~N}=1150)$

One state primary school in rural plain district in A city, Anhui province, $(\mathrm{n}=658)$

One state primary school in mountain area of rural district in Wuhu city, Anhui province, $(n=592)$

Group $2(\mathrm{~N}=1392)$

One primary school for children of Migrant Peasant Worker in unban district in Shanghai city, $(n=754)$

One primary school for children of Migrant Peasant Worker in suburb in Shanghai city, $(n=638)$

Group $3(N=1590)$

One state primary school in Unban district in Shanghai city, $(\mathrm{n}=869)$

One state primary school in suburb in Shanghai city, $(\mathrm{n}=721)$

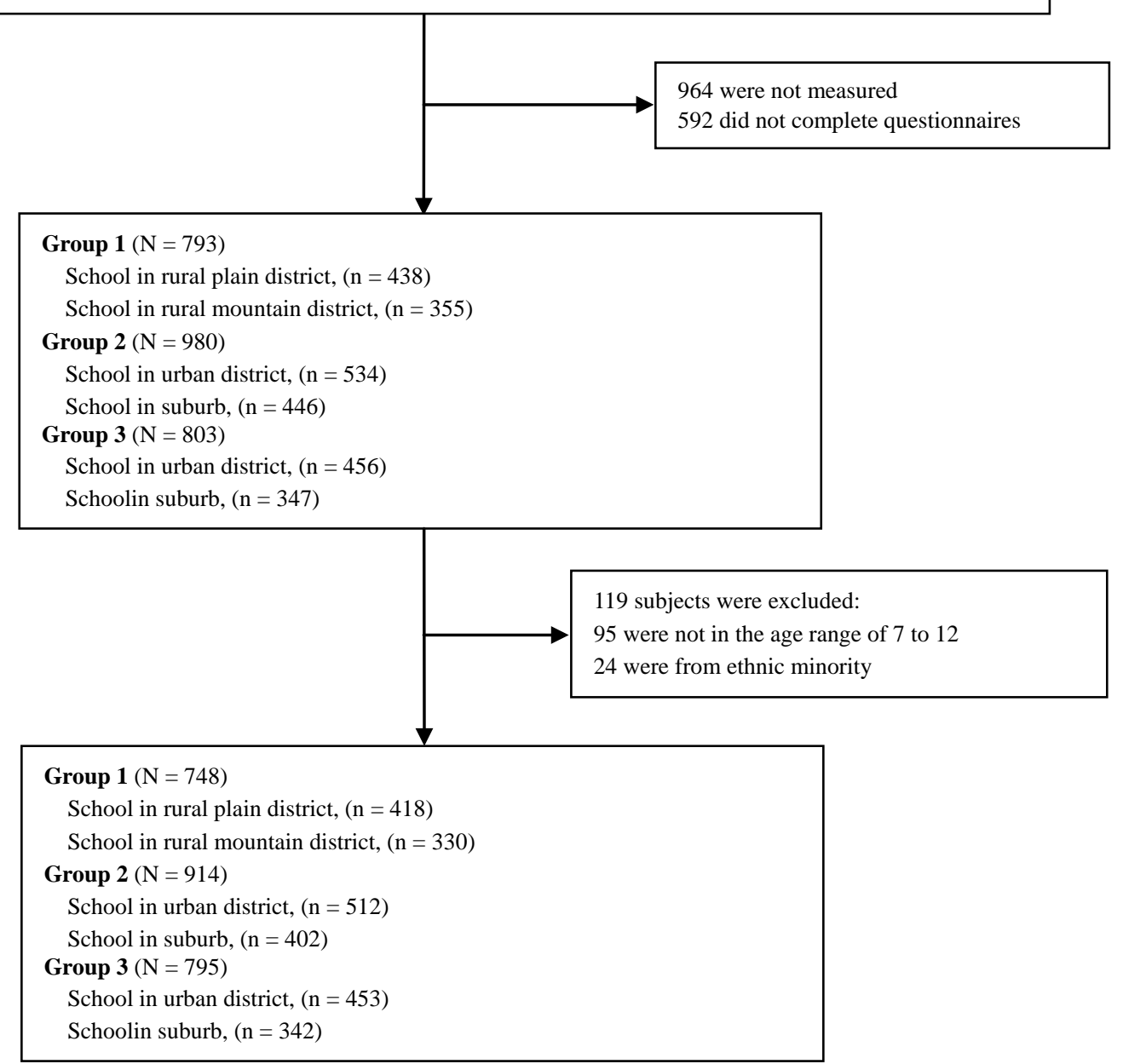

Figure 2.

Flow chart showing participants and the derivation of sample.

\section{Investigators}

The study comprised survey by questionnaires and anthropometric measurements. The seven investigators were graduate students majored in sport and health in K university in Shanghai. They were trained for one week. The training included special instruction for filling in questionnaires and for taking physical measurement. Each of them was put in charge of taking a specific physical measurement, and one of the authors was responsible to the questionnaire.

\section{Survey}

\section{Questionnaire}

We designed the questionnaire according to the Chinese National Nutrition and Health Survey, and National Health Interview Survey in USA. 
(http://www.moh.gov.cn/publicfiles/business/htmlfiles/wsb/pzc jd/200804/21290.htm.2010/12/10;

http://www.cdc.gov/nchs/nhis/quest_data_related_1997_forwar d.htm\#2012_NHIS.2010/11/06) A preliminary questionnaire was assessed by a pilot survey in March, 2010. According to the pilot survey, the questionnaire was slightly modified for ease of understanding and response. The questionnaire included questions concerning the occupation of child's parents, the child's parental education, the guardian's cognition of health, the child living environment and family status, the child learning and living condition, child's health status, child's lifestyle of diet and child's food intake frequency. We distributed the questionnaire to each school with the principal's consent. The questionnaires were handed out to the children and were collected by the teachers in charge of each class. Each child was asked to complete the questionnaire by consulting with their parent or guardian at home.

\section{Physical Measurements}

The physical characteristics measured in this study were as follows: height, weight, sitting height and body fat percentage. These physical indexes were chosen because height and weight are used to measure to assess the nutritional health status of a child, sitting height is often used as an indication of body proportion, and body fat percentage is used as an indication of body composition (Frisancho, 1981; Waterlow, Buzina, Keller, Lane, Nichaman, \& Tanner, 1977). The anthropometric equipmentswereZT-120 Weight-Height-Sitting height Meter (Wuxi Weighing Apparatus Company, China) and TBF-310 Body Fat Calculator (TANITA Company, Japan). The boys were measured wearing underpants only, and girls wore a t-shirt and a pair of light trousers. No subjects wore shoes. Heights were measured against metal column scales, knees not bent, arms at sides, shoulders relaxed, feet flat on the floor, and recorded to the nearest $.1 \mathrm{~cm}$. Sitting heights were measured sitting against metal column scales, and recorded to the nearest $.1 \mathrm{~cm}$. Weighing was done on platform scales, and the results were recorded to the nearest $.1 \mathrm{~kg}$. Body fat percentages were measured standing on platform scales after subject's feet were cleaned by paper.

(http://www.maine.gov/education/sh/heightandweight/heightwe ight.pdf .2011/03/02)

\section{Analytical Framework and Statistical Analyses}

There are many studies that have been conducted which explore the associations between socioeconomic factors and the children's physiques. Those researches noted that children who live in low-level socioeconomic status are at higher risk of growth retardation or obesity, and that socioeconomic status was a multi-dimensional construct that was most often measured by some combination of income, education, and occupation (Kuh, Power, Rodgers, 1991; Li \& Zhou, 2011; Ma, 2008). Therefore, in this report, parental occupation, parental education and family monthly income were selected as indices of socioeconomic status (Table 2).

In analysis of variance (ANOVA) and analysis of covariance (ANCOVA), the socioeconomic factors were reclassified because in the questionnaire the classified categories of occupation and family monthly income were excessive, and there were few parents with graduate degree in education. Three socioeconomic factors were reclassified as follow: 1) occupation: administrator \& office clerk personnel \& military personnel (OCP), professional (PRO), business service (BS), agriculture and water conservancy labors (AWCL), production of transport equipment operators (PTEO), unemployed (UNE), others $(\mathrm{OTH})$; 2) education: primary school or lower, junior high school, senior high school, college or higher; 3) family monthly income (yuan): $\leq 2000,2001$ - 5000, 5001 $\leq$. (uxin, et al.,2007)

The first analyses examined the differences of physique among three groups by ANOVA. The dependent variables included height, weight, sitting height, body fat percentage. Secondly, ANCOVA were applied to analyze the associations between children's physiques and socioeconomic factors by taking height, weight, sitting height, body fat percentage as dependent variables, socioeconomic factors (parental occupation, parental education, family monthly income) as independent variables, and age as a covariant. Thirdly, ANCOVA were used to assess differences of physiques among three groups by adjusting socioeconomic factor (parental occupation, parental education, family monthly income). The analyses were executed by taking physiques as a dependent variable, the group and socioeconomic factors as independent variables, and age as a covariant (Figure 3). All statistical analyses were performed using SPSS17.0 for Windows.

\begin{tabular}{|c|c|c|}
\hline $\begin{array}{l}\text { ANOVA } \\
\text { <Comparison among three groups }> \\
\text { Dependent variable, } \\
\text { Height, Weight, Sitting height, } \\
\text { Body fat percentage } \\
\text { Independent variable, } \\
\text { Group } \\
\text { Age }\end{array}$ & $\begin{array}{l}\text { ANCOVA } \\
<\text { Comparison among socioeconomic } \\
\text { factors }> \\
\text { Dependent variable } \\
\text { Height, Weight, Sitting height, } \\
\text { Body fat percentage } \\
\text { Independent variable } \\
\text { Parental occupation } \\
\text { Parental education } \\
\text { Family income per month } \\
\text { Covariant variable } \\
\text { Age }\end{array}$ & $\begin{array}{l}\text { ANCOVA } \\
\text { <Comparison among socioeconomic } \\
\text { factors and group> } \\
\text { Dependent variable } \\
\text { Height, Weight, Sitting height, } \\
\text { Body fat percentage } \\
\text { Independent variable } \\
\text { Parental occupation, Group } \\
\text { Parental education, Group } \\
\text { Family income per month, Group } \\
\text { Covariant variable } \\
\text { Age }\end{array}$ \\
\hline
\end{tabular}

Figure 3.

Conceptual frameworks for analyses. 
Table 2.

Socioeconomic status of families of the participants.

\begin{tabular}{|c|c|c|c|}
\hline & Rural resident N (\%) & Migrant peasant worker N (\%) & Citizen in Shanghai city $\mathrm{N}(\%)$ \\
\hline \multicolumn{4}{|l|}{$<$ Parental occupation $>$} \\
\hline Father & $714(95.5)$ & 875 (95.7) & $765(96.2)$ \\
\hline Administrator & $22(2.9)$ & $7(.8)$ & $60(7.6)$ \\
\hline Professional & $43(5.8)$ & $35(3.8)$ & $166(20.9)$ \\
\hline Office clerk personnel & $35(4.7)$ & $23(2.5)$ & $62(7.8)$ \\
\hline Business service & $113(15.1)$ & $172(18.8)$ & $159(20.0)$ \\
\hline Agriculture and water conservancy labors & $232(31.0)$ & $15(1.6)$ & $16(2.0)$ \\
\hline The production of transport equipment operators & $86(11.5)$ & $509(55.7)$ & $186(23.4)$ \\
\hline Military personnel & $8(1.1)$ & $0(0)$ & $1(.1)$ \\
\hline Unemployed & $40(5.4)$ & $22(2.4)$ & $22(2.8)$ \\
\hline Other & $135(18.1)$ & $92(10.1)$ & $93(11.7)$ \\
\hline Unknown & $34(4.6)$ & $39(4.3)$ & $30(3.8)$ \\
\hline Mother & $713(95.3)$ & $882(96.5)$ & $770(96.9)$ \\
\hline Administrator & $12(1.6)$ & $3(.8)$ & $33(4.2)$ \\
\hline Professional & $35(4.7)$ & $18(2.0)$ & $92(11.6)$ \\
\hline Office clerk personnel & $24(3.2)$ & $16(1.8)$ & $121(15.2)$ \\
\hline Business service & $106(14.2)$ & $193(21.1)$ & $227(28.6)$ \\
\hline Agriculture and water conservancy labors & $284(38.0)$ & $15(1.6)$ & $20(2.5)$ \\
\hline The production of transport equipment operators & $56(7.5)$ & $85(9.3)$ & $116(14.6)$ \\
\hline Military personnel & $1(.1)$ & $1(.1)$ & $0(0)$ \\
\hline Unemployed & $84(11.2)$ & $428(46.8)$ & $63(7.9)$ \\
\hline Other & $111(14.8)$ & $123(13.5)$ & $98(12.3)$ \\
\hline Unknown & $35(4.7)$ & $32(3.5)$ & $25(3.1)$ \\
\hline \multicolumn{4}{|l|}{$<$ Parental education $>$} \\
\hline Father & $714(95.5)$ & $873(95.5)$ & $765(96.2)$ \\
\hline Primary school or lower & $248(33.2)$ & $194(21.2)$ & $16(2.0)$ \\
\hline Junior high school & $382(51.1)$ & $414(45.3)$ & $188(23.7)$ \\
\hline Senior high school & $65(8.7)$ & $189(20.7)$ & $313(39.4)$ \\
\hline College & $18(2.4)$ & $74(8.1)$ & $224(28.2)$ \\
\hline Graduate & $1(.1)$ & $2(.2)$ & $24(3.0)$ \\
\hline Unknown & $34(4.6)$ & $41(4.5)$ & $30(3.8)$ \\
\hline Mother & $718(96.0)$ & $886(96.9)$ & $771(97.0)$ \\
\hline Primary school or lower & $391(52.3)$ & $387(42.3)$ & $54(6.8)$ \\
\hline Junior high school & $262(35.0)$ & 307 (33.6) & $279(35.1)$ \\
\hline Senior high school & $50(6.7)$ & $130(6.3)$ & $229(28.8)$ \\
\hline College & $9(1.2)$ & $58(6.4)$ & $200(25.2)$ \\
\hline Graduate & $2(.3)$ & $4(.4)$ & $9(1.1)$ \\
\hline Unknown & $34(4.6)$ & $28(3.1)$ & $24(3.0)$ \\
\hline$<$ Family monthly income, yuan $>$ & 575 (76.9) & 835 (91.4) & $749(94.2)$ \\
\hline$\leq 1000$ & $173(23.1)$ & $66(7.2)$ & $12(1.5)$ \\
\hline $1001 \sim 2000$ & $194(25.9)$ & $202(22.1)$ & $73(9.2)$ \\
\hline $2001 \sim 3000$ & $114(15.2)$ & $153(16.7)$ & $85(10.7)$ \\
\hline $3001 \sim 4000$ & $32(4.3)$ & $101(11.1)$ & 85 (10.7) \\
\hline $4001 \sim 5000$ & $21(2.8)$ & 96 (10.5) & $86(10.8)$ \\
\hline $5001 \sim 6000$ & $14(1.9)$ & $55(6.0)$ & $114(14.3)$ \\
\hline $6001 \sim 7000$ & $8(1.1)$ & $47(5.1)$ & $66(8.3)$ \\
\hline $7001 \sim 8000$ & $5(.7)$ & $21(2.3)$ & $65(8.2)$ \\
\hline $8001 \sim 10000$ & $5(.7)$ & $49(5.4)$ & 88 (11.1) \\
\hline $10000<$ & $9(1.2)$ & $45(4.9)$ & $75(9.4)$ \\
\hline Unknown & $173(23.1)$ & $79(8.6)$ & $46(5.8)$ \\
\hline
\end{tabular}

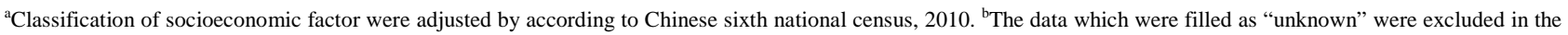
analysis. 


\section{Results}

Table 2 presents the frequencies and proportions of children's parental occupation, parental education and family monthly income.

For the fathers, a high proportion of the occupations were AWCL with $31 \%$, OTH with $18 \%$ and BS with $15 \%$ in group 1 , PTEO with $56 \%$ and BS with $19 \%$ in group 2, and PTEO with $23 \%$, PRO with $21 \%$ and BS with $20 \%$ in group 3 . For mothers, those were as follows: AWCL with $38 \%$, OTH with $15 \%$ and BS with $14 \%$ in group 1, UNE with $47 \%$, BS with $21 \%$ and OTH with $14 \%$ in group 2 , and BS with $29 \%$, OCP with $15 \%$ and PTEO with $15 \%$ in group 3 . Group 1 tended to have a high proportion of AWCL in both parents, Group 2 did PTEO in father and UNE in mother, and group 3 did PRO, OCP and AD (administrator) in both parents.

Regarding the parental education, father's education level of junior high school or lower was $84 \%$ in group $1,66 \%$ in group 2 , and $26 \%$ in group 3 . The career of college or higher was $3 \%$ in group $1,8 \%$ in group 2 , and $31 \%$ in group 3 . For mothers, junior high school or lower was $85 \%$ in group $1,76 \%$ in group 2 and $42 \%$ in group 3 . The career of college or higher was $2 \%$ in group 1,7\% in group 2 and $26 \%$ in group 3 . The education level was high in ascending order of group 1, group 2 and group 3 in both father and mother. Father's level was higher than mother's in all groups.

Family monthly income (yuan) was high in ascending order of group 1, group 2 and group 3. The income of 2000 or less was $49 \%$ in group 1, $29 \%$ in group 2, and $11 \%$ in group 3. The income of 5001 or higher was $6 \%$ in group 1, 23\% in group 2, and $51 \%$ in group 3 .

\section{Comparison of Physique among Three Groups by ANOVA}

Comparisons of physique among three groups were presented in Figure 4. There were significant differences in all physical indexes, no matter what boys and girls $(\mathrm{P}<.001)$. Children's physiques of group 2 were smaller than group 3 except for sitting height (7-year-old boys, 12-year-old girls) and body fat percentage (7-year-old boys, 7 to 9 -year-old girls). In all age, regardless of gender, physiques in group 2 were bigger than group 1.

\section{Relationship between Physique and Socioeconomic Factor by ANCOVA}

Tables 3 and 4 show associations of physiques with parental occupation. In both boys and girls all indexes displayed statistically significant associations with parental occupations (P $<$.001). Among the occupations in fathers, AWCL and UNE had relatively small physiques, and OCP, PRO and PTEO showed big physiques in both boys and girls. In respect of mother's occupations, AWCL had relatively small physiques in boys. Similarly, AWCL had relatively small physiques while OCP, PRO, BS and PTEO showed big physiques in girls.

Table 3.

Comparison of physiques by father's occupation.

\begin{tabular}{|c|c|c|c|c|c|c|c|c|c|c|c|c|c|c|c|c|}
\hline & \multicolumn{4}{|c|}{ Height } & \multicolumn{4}{|c|}{ Weight } & \multicolumn{4}{|c|}{ Sitting height } & \multicolumn{4}{|c|}{ Body fat percentage } \\
\hline & Beta & $(95 \% \mathrm{CI})$ & F-value & P-value & Beta & $(95 \% \mathrm{CI})$ & F-value & P-value & Beta & $(95 \% \mathrm{CI})$ & F-value & P-value & Beta & $(95 \% \mathrm{CI})$ & F-value & P-value \\
\hline \multicolumn{17}{|l|}{$<$ Boys $>$} \\
\hline Occupation $^{\mathrm{a}}$ & & & 15.17 & $<.001$ & & & 14.32 & $<.001$ & & & 17.04 & $<.001$ & & & 16.64 & $<.001$ \\
\hline OCP & .85 & $(-1.00-2.7)$ & & & 1.79 & $(-.09-3.66)$ & & & -.34 & $(-1.40-.71)$ & & & .68 & $(-.59-1.96)$ & & \\
\hline PRO & 1.92 & $(.13-3.72)$ & & & .92 & $(-.90-2.74)$ & & & .25 & $(-.77-1.28)$ & & & 2.10 & $(.86-3.33)$ & & \\
\hline BS & .12 & $(-1.40-2.7)$ & & & -.02 & $(-1.56-1.53)$ & & & .21 & $(-.66-1.08)$ & & & .58 & $(-.47-1.63)$ & & \\
\hline AWCL & -5.05 & $(-6.76--3.34)$ & & & -4.51( & $(-6.25--2.78)$ & & & -2.93 & $(-3.90--1.95)$ & & & -2.60 & $(-3.78--1.42)$ & & \\
\hline PTEO & 1.39 & $(.01-2.78)$ & & & 1.91 & $(.50-3.32)$ & & & 1.08 & $(.29-1.87)$ & & & 2.00 & $(1.04-2.95)$ & & \\
\hline UNE & -1.63 & $(-4.10-.84)$ & & & -1.89 & $(-4.40-.61)$ & & & -1.56 & $(-2.97--.16)$ & & & -.50 & $(-2.20-1.19)$ & & \\
\hline $\mathrm{OTH}^{\mathrm{b}}$ & - & & & & - & & & & - & & & & - & & & \\
\hline \multicolumn{17}{|l|}{$<$ Girls $>$} \\
\hline Occupation & & & 15.58 & $<.001$ & & & 14.59 & $<.001$ & & & 15.02 & $<.001$ & & & 11.97 & $<.001$ \\
\hline OCР & 3.08 & $(1.09-5.07)$ & & & 2.10 & $(.45-3.76)$ & & & .96 & $(-.14-2.05)$ & & & .62 & $(-.68-1.91)$ & & \\
\hline PRO & 4.58 & $(2.65-6.51)$ & & & 2.11 & $(.51-3.72)$ & & & 1.59 & $(.53-2.65)$ & & & .41 & $(-.85-1.67)$ & & \\
\hline BS & 1.71 & $(.01-3.41)$ & & & 1.69 & $(.27-3.1)$ & & & 1.01 & $(.07-1.95)$ & & & .48 & $(-.63-1.59)$ & & \\
\hline AWCL & -3.72 & $(-5.69--1.75)$ & & & -3.21( & $(-4.85--1.57)$ & & & -2.43 & $(-3.52--1.35)$ & & & -2.92 & $(-4.21--1.64)$ & & \\
\hline PTEO & 3.14 & $(1.61-4.67)$ & & & 2.95 & $(1.68-4.22)$ & & & 1.88 & $(1.04-2.72)$ & & & 1.73 & $(.73-2.73)$ & & \\
\hline UNE & -1.79 & $(-4.73-1.14)$ & & & -1.54 & $(-3.98-.90)$ & & & -.09 & $(-1.71-1.52)$ & & & -1.46 & $(-3.38-.45)$ & & \\
\hline OTH & - & & & & - & & & & - & & & & - & & & \\
\hline Age (years) & 4.62 & $(4.29-4.95)$ & 765.69 & $<.001$ & 2.68 & $(2.40-2.95)$ & 371.25 & $<.001$ & 1.98 & $(1.80-2.16)$ & 464.42 & $<.001$ & .50 & $(.29-.71)$ & 21.04 & $<.001$ \\
\hline
\end{tabular}

aOCP: Office clerk personnel, PRO: Professional, BS: Business service, AWCL: Agriculture and water conservancy labors, PTEO: The production of transport equipment operators, UNE: Unemployed, OTH: Other. ${ }^{\mathrm{b}}$ OTH was set as reference. 
Height

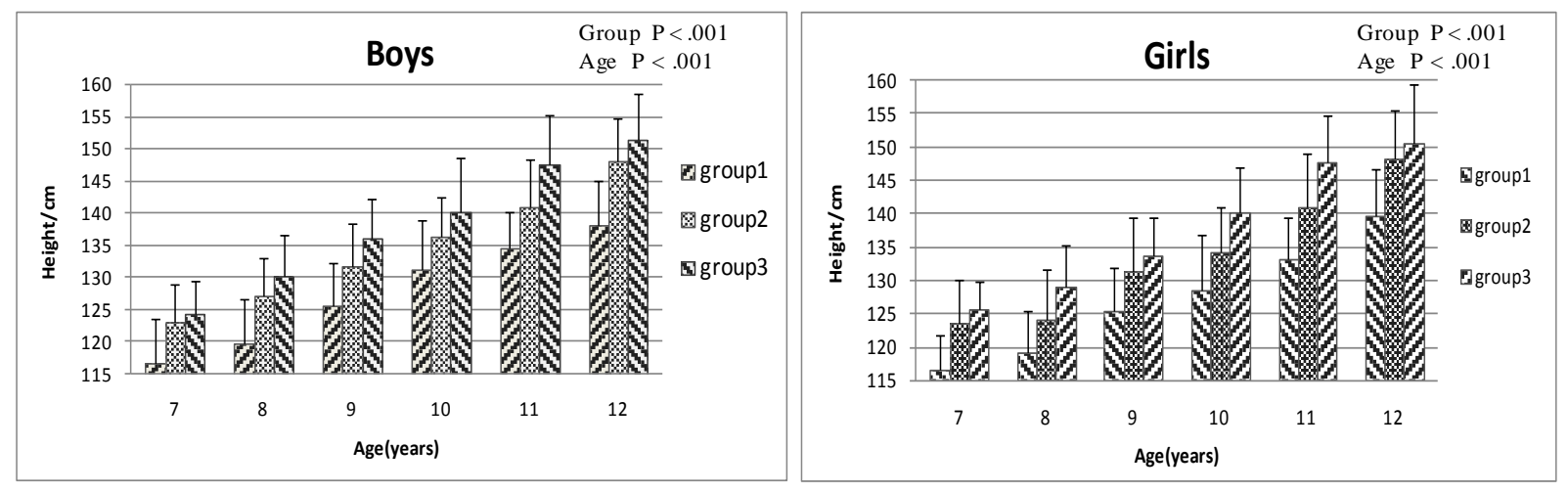

Weight
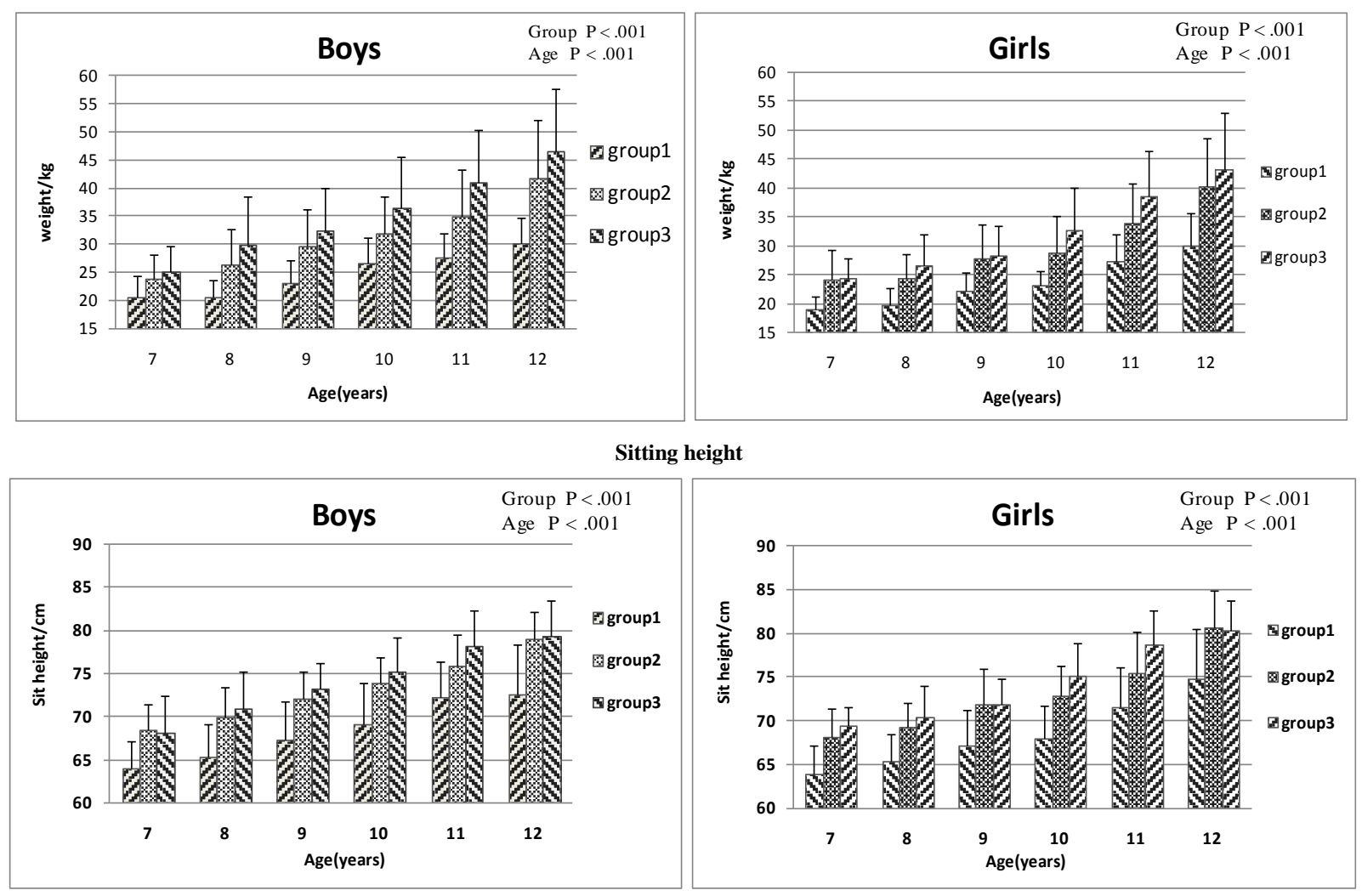

Body fat percentage

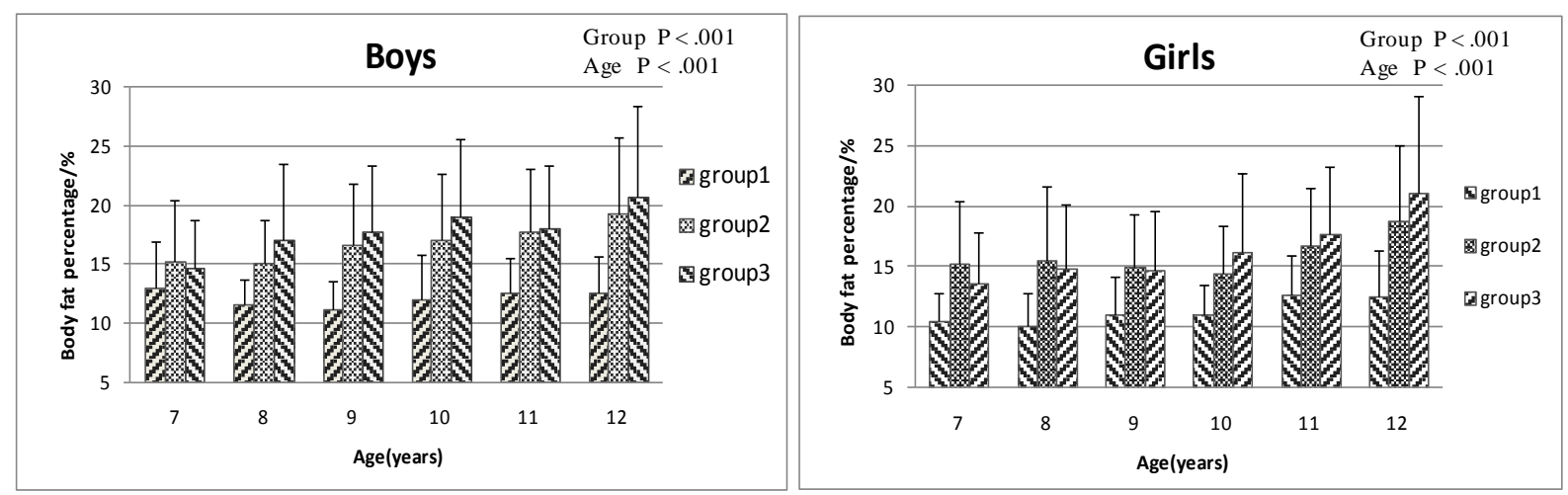

Figure 4.

Comparisons of physiques among three groups by ANOVA. 
Table 4.

Comparison of physiques by mother's occupation.

\begin{tabular}{|c|c|c|c|c|c|c|c|c|c|c|c|c|c|c|c|c|}
\hline & \multicolumn{4}{|c|}{ Height } & \multicolumn{4}{|c|}{ Weight } & \multicolumn{4}{|c|}{ Sitting height } & \multicolumn{4}{|c|}{ Body fat percentage } \\
\hline & Beta & (95\%CI ) & F-value & P-value & Beta & $(95 \% \mathrm{CI})$ & F-value & P-value & Beta & $(95 \% \mathrm{CI})$ & F-value & P-value & Beta & $(95 \% \mathrm{CI})$ & F-value & P-value \\
\hline \multicolumn{17}{|l|}{$<$ Boys $>$} \\
\hline Occupation $^{\mathrm{a}}$ & & & 13.80 & $<.001$ & & & 16.55 & $<.001$ & & & 13.49 & $<.001$ & & & 12.51 & $<.001$ \\
\hline OCP & 1.13 & $(-.66-2.92)$ & & & 2.18 & $(.37-3.99)$ & & & -.70 & $(-1.74-.34)$ & & & 1.35 & $(.11-2.59)$ & & \\
\hline PRO & -.71 & $(-2.12-2.02)$ & & & .22 & $(-1.89-2.33)$ & & & -.46 & $(-1.67-.75)$ & & & .54 & $(-.91-1.99)$ & & \\
\hline BS & .20 & $(-1.21-1.61)$ & & & 1.21 & $(-.21-2.63)$ & & & -.23 & $(-1.05-.58)$ & & & 1.07 & $(.09-2.04)$ & & \\
\hline AWCL & -5.55 & $(-6.76--3.34)$ & & & -5.40 & $(-6.99--3.81)$ & & & -3.31 & $(-4.23--2.40)$ & & & -2.80 & $(-3.89--1.71)$ & & \\
\hline PTEO & -1.07 & $(-2.72-.57)$ & & & -.28 & $(-1.93-1.38)$ & & & -.54 & $(-1.49-.41)$ & & & .34 & $(-.80-1.47)$ & & \\
\hline UNE & -.24 & $(-1.61-1.14)$ & & & .17 & $(-1.21-1.56)$ & & & -.22 & $(-.58-1.01)$ & & & .98 & $(.03-1.94)$ & & \\
\hline $\mathrm{OTH}^{\mathrm{b}}$ & - & & & & - & & & & - & & & & - & & & \\
\hline \multicolumn{17}{|l|}{$<$ Girls $>$} \\
\hline Occupation & & & 19.82 & $<.001$ & & & 15.62 & $<.001$ & & & 17.48 & $<.001$ & & & 9.96 & $<.001$ \\
\hline ОСР & 4.46 & $(2.39-6.52)$ & & & 2.90 & $(1.17-4.63)$ & & & 1.33 & $(.18-2.48)$ & & & .75 & $(-.61-2.10)$ & & \\
\hline PRO & 4.23 & $(1.97-6.49)$ & & & 1.90 & $(.01-3.80)$ & & & .88 & $(-.38-2.14)$ & & & -.18 & $(-1.67-1.30)$ & & \\
\hline BS & 2.17 & $(.50-3.84)$ & & & 1.99 & $(.59-3.39)$ & & & .75 & $(-.187-1.68)$ & & & 1.12 & $(.03-2.22)$ & & \\
\hline AWCL & -4.73 & $(-6.60--2.86)$ & & & -3.59 & $(-5.16--2.03)$ & & & -3.22 & $(-4.27--2.18)$ & & & -2.57 & $(-3.80--1.34)$ & & \\
\hline PTEO & 2.90 & $(.88-4.92)$ & & & 2.81 & $(1.12-4.50)$ & & & 1.25 & $(.13-2.38)$ & & & 1.59 & $(.26-2.91)$ & & \\
\hline UNE & .85 & $(-.81-2.51)$ & & & 1.16 & $(-.24-2.55)$ & & & -.54 & $(-.39-1.46)$ & & & .80 & $(-.29-1.89)$ & & \\
\hline ОTH & - & & & & - & & & & - & & & & - & & & \\
\hline Age (years) & 4.64 & $(4.32-4.96)$ & 795.39 & $<.001$ & 2.72 & $(2.45-2.994)$ & 389.18 & $<.001$ & 2.00 & $(1.82-2.18)$ & 475.56 & $<.001$ & .54 & $(.33-.75)$ & 24.98 & $<.001$ \\
\hline
\end{tabular}

aCP: Office clerk personnel, PRO: Professional, BS: Business service, AWCL: Agriculture and water conservancy labors, PTEO: The production of transport equipment operators, UNE: Unemployed, OTH: Other. ${ }^{\mathrm{b}} \mathrm{OTH}$ was set as reference.

There were strong associations between parental education and all physical indexes (Table $5, \mathrm{P}<.001$ ). In both boys and girls, children of fathers with higher education were bigger than those that had lower education. With regard to mothers' education, the results yielded almost the same as fathers'.

Family monthly income was significantly associated with children's physiques $(\mathrm{P}<.001)$. In both sexes, higher was the family monthly income, bigger or higher were the physiques of children in all indexes (Table 6).

\section{Associations of the Physiques with Socioeconomic Factors and Group by ANCOVA}

Tables 7 and 8 show that there were strong associations (boys and girls) between physique and group in all indexes ( $\mathrm{P}$ $<.001$ ), but physiques hardly had any associations with socioeconomic factors. After the adjustment by socioeconomic factors, the sizes of physiques were big in descending order of group 3, group 2 and group 1, while ANCOVA was performed taking socioeconomic factors and group as independent variables when age was taken as a covariate.

\section{Discussion}

This study showed significant differences in physiques among three groups. Physiques of MPW's children were smaller than children of citizen in Shanghai City, and MPW's children had bigger physiques than rural children. The former finding is consistent with previous studies that reported MPW's children were smaller than urban children (Bradley, Kelleher, 1992; Chen et al., 2010; Chen et al., 2006). The latter finding is also consistent with the results from a previous study (Yan, 2005) We also found that there were strong associations between physiques and each socioeconomic factor such as family income, parental occupation and parental education. These findings were consistent with studies that children from high SES family have bigger physiques than those from low SES family (Morton, et al., 2002; McBride, 1990; Mahoney, Kaiser et al., 1999; McLoyd, 1998; Ma, Wu, Yang, 2010; NICHD Early Child Care Research Network, 1998; Ortega, Fang, Perez, et al., 2007; Parke, Coltrane, Duffy, Buriel, Dennis et al., 2004; Rona, Chinn, 1991; Solinger, 1999; Mohanty, Woolhandler, Himmelstein, Pati, Carrasquillo, Bor, 2005; Slesinger, Christenson, Cautley, 1986; Stamatakis, Wardle, Cole, 2010). Finally, by the ANCOVA in which both socioeconomic factors and groups were taken as independent variables and age was taken as a covariate, although strong associations between physiques and group were identified, there were hardly associations between socioeconomic factors and physiques.

At first, the associations between physiques and socioeconomic factors were discussed. In this study, we examined parental occupation, parental educational career and family monthly income among socioeconomic factors.

In this study, children whose parents were AWCL had relatively small physiques, and OCP and PRO did big physiques in 
Table 5.

Associations between parental education and physiques.

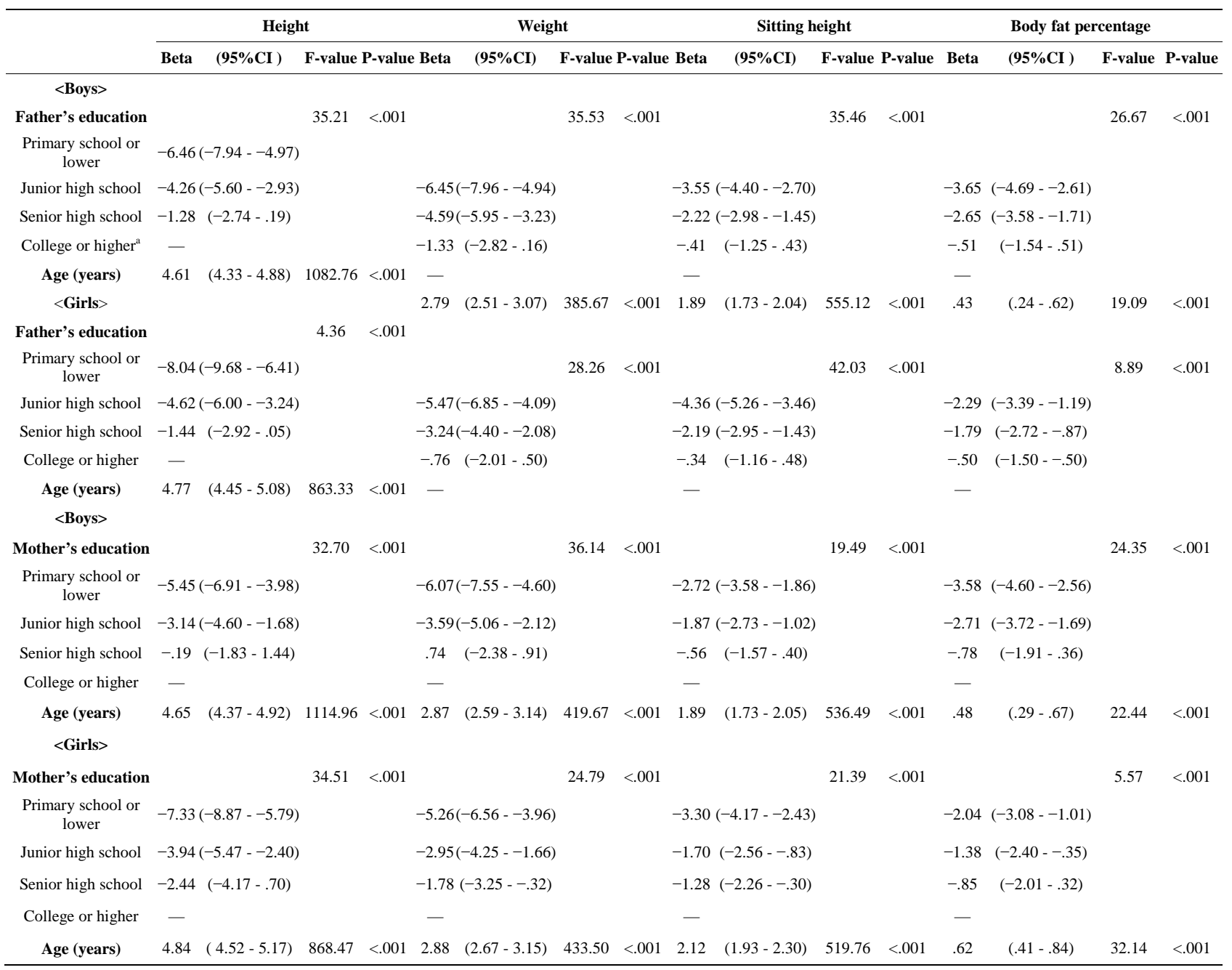

${ }^{\mathrm{a} C o l l e g e ~ o r ~ h i g h e r ~ w a s ~ s e t ~ a s ~ r e f e r e n c e . ~}$

Table 6.

Associations between family monthly income and physiques.

\begin{tabular}{|c|c|c|c|c|c|c|c|c|c|c|c|c|c|c|c|c|}
\hline & \multicolumn{4}{|c|}{ Height } & \multicolumn{4}{|c|}{ Weight } & \multicolumn{4}{|c|}{ Sitting height } & \multicolumn{4}{|c|}{ Body fat percentage } \\
\hline & Beta & $(95 \% \mathrm{CI})$ & F-value & P-value & Beta & $(95 \% \mathrm{CI})$ & F-value & P-value & Beta & $(95 \% \mathrm{CI})$ & F-value & P-value & Beta & $(95 \% \mathrm{CI})$ & F-value & P-value \\
\hline \multicolumn{17}{|l|}{$<$ Boys $>$} \\
\hline$\leq 2000$ & -5.68 & $(-6.77--5.0)$ & & & -4.88 & $(-5.97--3.79)$ & & & -3.07 & $(-3.70--2.43)$ & & & -2.87 & $(-3.62--2.11)$ & & \\
\hline $2001-5000$ & -1.93 & $(-2.99--.87)$ & & & -1.74 & $(-2.80--.68)$ & & & -1.22 & $(-1.84--.60)$ & & & -1.49 & $(-2.22--.76)$ & & \\
\hline $5001 \leq^{\mathrm{a}}$ & - & & & & - & & & & - & & & & - & & & \\
\hline Age (years) & 4.73 & $(4.45-5.01)$ & & & 2.97 & $(2.69-3.25)$ & 435.46 & $<.001$ & 1.93 & $(1.77-2.10)$ & 536.81 & $<.001$ & .54 & $(.35-.73)$ & 30.23 & $<.001$ \\
\hline \multicolumn{17}{|l|}{$<$ Girls $>$} \\
\hline $\begin{array}{l}\text { Family monthly } \\
\text { income }\end{array}$ & & & 50.35 & $<.001$ & & & 38.55 & $<.001$ & & & 34.48 & $<.001$ & & & 13.05 & $<.001$ \\
\hline$\leq 2000$ & -6.22( & $(-7.46--4.99)$ & & & -4.43 & $(-5.48--3.38)$ & & & -2.92 & $(-3.61--2.22)$ & & & -1.94 & $(-2.79--1.09)$ & & \\
\hline 2001-5000 & -2.10 & $(-3.33--.87)$ & & & -.89 & $(-1.93-.15)$ & & & -1.13 & $(-1.82--.44)$ & & & -.07 & $(-.91-.77)$ & & \\
\hline Age (years) & 5.00 & $(4.64-5.31)$ & 858.88 & $<.001$ & 3.00 & $(2.68-3.24)$ & 423.51 & $<.001$ & 2.14 & $(1.95-2.33)$ & 504.53 & $<.001$ & .63 & $(.41-.86)$ & 29.66 & $<.001$ \\
\hline
\end{tabular}

${ }^{a} 5001 \leq$ was set as reference. 
J.-K. LU ET AL.

Table 7.

Associations of physiques with occupation, education, family monthly income, and group by ANCOVA, boys.

\begin{tabular}{|c|c|c|c|c|c|c|c|c|c|c|c|c|c|c|c|c|}
\hline & & Heig & & & & Weigh & & & & Sitting he & eight & & & Body fat per & rcentage & \\
\hline & Beta & $(95 \% \mathrm{CI})$ & F-value & P-value & Beta & $(95 \% \mathrm{CI})$ & F-value & P-value & Beta & $(95 \% \mathrm{CI})$ & F-value & P-value & Beta & $(95 \% \mathrm{CI})$ & F-value I & P-value \\
\hline $\begin{array}{c}\text { Father's } \\
\text { occupation }\end{array}$ & & & .87 & & & & 1.93 & & & & 2.24 & $<.05$ & & & 2.81 & $<.05$ \\
\hline Group & & & 155.60 & $<.001$ & & & 149.78 & $<.001$ & & & 168.00 & $<.001$ & & & 102.89 & $<.001$ \\
\hline 1 & -6.80 & $(-9.24--4.37)$ & & & -7.63 & $(-10.12--5.15)$ & & & -3.96( & $(-5.34--2.57)$ & & & -3.41 & $(-5.17--1.64)$ & & \\
\hline $2^{a}$ & - & & & & - & & & & - & & & & - & & & \\
\hline 3 & 4.11 & $(1.40-6.81)$ & & & 4.81 & $(2.04-7.57)$ & & & .84 & $(-.70-2.37)$ & & & 2.55 & $(.59-4.51)$ & & \\
\hline Age & 4.86 & $(4.61-5.10)$ & 1512.27 & $<.001$ & 3.04 & $(2.79-3.29)$ & 569.12 & $<.001$ & 2.04 & $(1.90-2.18)$ & 828.55 & $<.001$ & .62 & $(.45-.80)$ & 47.93 & $<.001$ \\
\hline $\begin{array}{l}\text { Mother's } \\
\text { occupation }\end{array}$ & & & 1.35 & & & & 1.01 & & & & 3.11 & $<.05$ & & & .72 & \\
\hline Group & & & 160.56 & $<.001$ & & & 136.52 & $<.001$ & & & 198.15 & $<.001$ & & & 106.03 & $<.001$ \\
\hline 1 & -6.52 & $(-8.82--4.22)$ & & & -8.00 & $(-10.32--5.65)$ & & & -4.14 & $(-5.44--2.83)$ & & & 4.24 & $(-5.89--2.59)$ & & \\
\hline 3 & 4.93 & $(2.61-7.25)$ & & & 4.30 & $(1.95-6.65)$ & & & 1.31 & $(-.01-2.62)$ & & & 2.03 & $(.37-3.70)$ & & \\
\hline Age & 4.86 & $\begin{array}{c}(4.62-5.12) \\
1503.69<.001\end{array}$ & & & 3.08 & $(2.83-3.33)$ & 586.10 & $<.001$ & 2.07 & $(1.93-2.21)$ & 845.04 & $<.001$ & .64 & $(.46-.82)$ & 50.60 & $<.001$ \\
\hline $\begin{array}{l}\text { Father's } \\
\text { education }\end{array}$ & & & .37 & & & & .34 & & & & 1.93 & & & & 1.16 & \\
\hline Group & & & 68.85 & $<.001$ & & & 70.12 & $<.001$ & & & 58.90 & $<.001$ & & & 45.18 & $<.001$ \\
\hline 1 & -5.98 & $(-10.88--1.08)$ & & & -9.50 & $(-14.52--4.49)$ & & & -3.15 & $(-5.94--.37)$ & & & -4.51 & $(-8.074--.94)$ & & \\
\hline 2 & - & & & & - & & & & - & & & & - & & & \\
\hline 3 & 5.57 & $(3.18-7.96)$ & & & 3.05 & $(.60-5.50)$ & & & 1.85 & $(.49-3.21)$ & & & 1.96 & $(.22-3.71)$ & & \\
\hline Age & 4.92 & $(4.68-5.17)$ & 1537.70 & $<.001$ & 3.12 & $(2.87-3.37)$ & 589.82 & $<.001$ & 2.10 & $(1.96-2.24)$ & 863.60 & $<.001$ & .65 & $(.47-.82)$ & 49.76 & $<.001$ \\
\hline $\begin{array}{l}\text { Mother's } \\
\text { education }\end{array}$ & & & .63 & & & & .42 & & & & .94 & & & & .53 & \\
\hline Group & & & 80.35 & $<.001$ & & & 74.93 & $<.001$ & & & 68.83 & $<.001$ & & & 44.89 & $<.001$ \\
\hline 3 & 7.08 & $(4.59-9.59)$ & & & 5.47 & $(2.93-8.01)$ & & & 2.48 & $(1.04-3.92)$ & & & 2.40 & $(.59-4.20)$ & & \\
\hline Age & 4.88 & $(4.64-5.12)$ & $<1567.60$ & $<.001$ & 3.11 & $(2.86-3.35)$ & 615.83 & $<.001$ & 2.05 & $(1.91-2.19)$ & 837.88 & $<.001$ & .64 & $(.47-.81)$ & 51.83 & $<.001$ \\
\hline $\begin{array}{c}\text { Family } \\
\text { monthly } \\
\text { income }\end{array}$ & & & 3.04 & $<.05$ & & & .58 & & & & .33 & & & & 1.66 & \\
\hline Group & & & 135.67 & $<.001$ & & & 122.80 & $<.001$ & & & 134.64 & $<.001$ & & & $\begin{array}{l}79.08 \\
<.001\end{array}$ & $<.001$ \\
\hline 1 & -9.93 & $(-12.83--7.02)$ & & & -7.79 & $(-10.71--4.87)$ & & & -5.56( & $(-7.24--3.89)$ & & & -3.85 & $(-5.91-1.78)$ & & \\
\hline 2 & - & & & & - & & & & - & & & & - & & & \\
\hline 3 & 3.63 & $(2.16--5.10)$ & & & 3.59 & $(2.12-5.07)$ & & & .94 & $(.09-1.79)$ & & & 1.38 & $(.33-2.43)$ & & \\
\hline Age & 4.93 & $(4.68-5.18)$ & 1488.72 & $<.001$ & 3.16 & $(2.90-3.41)$ & 605.98 & $<.001$ & 2.06 & $(1.91-2.20)$ & 780.33 & $<.001$ & .68 & $(.50-.85)$ & 55.36 & $<.001$ \\
\hline
\end{tabular}

${ }^{\mathrm{a}}$ Group 2 was set as reference.

both boys and girls. Kuh DL et al. have reported that children (7, 10, 11 yrs) whose fathers' occupations were non-manual work had taller than those with manual work (Kuh, Power, Rodgers, 1991). AWCL is considered to belong to manual work, and OCP and PRO to non-manual work according to Registrar General's categories in UK (Black, Morris, Smith, Townsend, Whitehead, 1988; Kuh, Power, Rodgers, 1991). Therefore, our findings are generally consistent with the report. Parents with non-manual occupation can provide their children an array of services, goods such as proper clothing, housing and food, which are beneficial to children. Many children of parents with manual occupation lack access to those same resources and benefits, thus putting them at risk for underweight (Halldorsson,
Kunst, Kohler, Mackenbach, 2000; Rona, Chinn,1991). In our data, occupations such as OCP and PRO are regarded as non-manual occupation, and they had a tendency to earn high wage. Therefore, similar mechanisms are assumed to have worked on the research populations.

Parental educational career has a definite association with children's physiques, that is, children with higher parental educational career have a tendency towards bigger physiques. Many studies showed that parental education has a profound influence on child's physical growth. (Parke, Coltrane, Duffy, Buriel, Dennis et al., 2004; Rona \& Chinn, 1991; Solinger, 1999). Physiques of children whose parents have high-level education are bigger than those whose parents had low-level 
Table 8.

Associations of physiques with occupation, education, family monthly income, and group by ANCOVA, girls.

\begin{tabular}{|c|c|c|c|c|c|c|c|c|c|c|c|c|c|c|c|c|}
\hline & \multicolumn{4}{|c|}{ Height } & \multicolumn{4}{|c|}{ Weight } & \multicolumn{4}{|c|}{ Sitting height } & \multicolumn{4}{|c|}{ Body Fat Percentage } \\
\hline & Beta & $(95 \% \mathrm{CI})$ & F-value & P-value & Beta & $(95 \% \mathrm{CI})$ & F-value & P-value & Beta & $(95 \% \mathrm{CI})$ & F-value & P-value & Beta & $(95 \% \mathrm{CI})$ & F-value & P-value \\
\hline $\begin{array}{l}\text { Father's } \\
\text { occupation }\end{array}$ & & & 1.13 & & & & 1.05 & & & & .76 & & & & 1.05 & \\
\hline Group & & & 83.42 & $<.001$ & & & 82.48 & $<.001$ & & & 106.76 & $<.001$ & & & 36.48 & $<.001$ \\
\hline 1 & -5.32 & $(-8.09--2.57)$ & & & -4.92 & $(-7.26--2.59)$ & & & -1.77 & $(-3.28--.26)$ & & & -3.91 & $(-5.85--1.97)$ & & \\
\hline $2^{\mathrm{a}}$ & - & & & & - & & & & - & & & & - & & & \\
\hline 3 & 7.29 & $(4.34-10.25)$ & & & 4.38 & $(1.88-6.88)$ & & & 3.30 & $(1.68-4.92)$ & & & 1.45 & $(-.62-3.53)$ & & \\
\hline Age & 5.06 & $(4.76-5.36)$ & 1093.38 & $<.001$ & 3.03 & $(2.78-3.29)$ & 549.71 & $<.001$ & 2.25 & $(2.09-2.42)$ & 722.55 & $<.001$ & .73 & $(.52-.95)$ & 46.69 & $<.001$ \\
\hline $\begin{array}{l}\text { Mother's } \\
\text { occupation }\end{array}$ & & & 1.80 & & & & .90 & & & & .51 & & & & .49 & \\
\hline Group & & & 104.98 & $<.001$ & & & 87.93 & $<.001$ & & & 139.69 & $<.001$ & & & 39.54 & $<.001$ \\
\hline 1 & -5.63 & $(-8.56--2.70)$ & & & -3.92 & $(-6.37--1.47)$ & & & -2.76 & $(-4.36--1.16)$ & & & 2.35 & $(-4.36--.34)$ & & \\
\hline 2 & - & & & & - & & & & - & & & & - & & & \\
\hline Age & 5.03 & $(4.74-5.33)$ & 1122.30 & $<.001$ & 3.06 & $(2.82-3.31)$ & 594.04 & $<.001$ & 2.25 & $(2.09-2.41)$ & 749.54 & $<.001$ & .75 & $(.55-.96)$ & 53.37 & $<.001$ \\
\hline $\begin{array}{l}\text { Father's } \\
\text { education }\end{array}$ & & & 1.11 & & & & .74 & & & & 2.58 & & & & .74 & \\
\hline Group & & & 50.73 & $<.001$ & & & 57.35 & $<.001$ & & & 60.51 & $<.001$ & & & 30.23 & $<.001$ \\
\hline 1 & -6.17 & $(-11.12--1.21)$ & & & -8.05 & $-12.23--3.87)$ & & & -5.21 & $(-7.92--2.50)$ & & & -3.31 & $(-6.77-.15)$ & & \\
\hline 2 & - & & & & - & & & & - & & & & - & & & \\
\hline 3 & 4.85 & $(2.19-7.52)$ & & & 1.84 & $(-.41-4.09)$ & & & 1.07 & $(-.39-2.53)$ & & & -.78 & $(-2.64-1.08)$ & & \\
\hline Age & 4.98 & $(4.69-5.27)$ & 1133.19 & $<.001$ & 3.01 & $(2.77-3.26)$ & 581.97 & $<.001$ & 2.26 & $(2.10-2.42)$ & 776.52 & $<.001$ & .77 & $(.57-.98)$ & 55.94 & $<.001$ \\
\hline $\begin{array}{l}\text { Mother's } \\
\text { education }\end{array}$ & & & 1.61 & & & & .22 & & & & 1.08 & & & & 1.00 & \\
\hline Group & & & 60.01 & $<.001$ & & & 56.79 & $<.001$ & & & 67.73 & $<.001$ & & & 25.55 & $<.001$ \\
\hline 1 & -4.57 & $(-10.92-1.77)$ & & & -6.88 & $-12.24--1.51)$ & & & -3.29 & $(-6.79-.21)$ & & & -1.79 & $(-6.22-2.65)$ & & \\
\hline 2 & - & & & & - & & & & - & & & & - & & & \\
\hline 3 & 7.49 & $(4.24-10.75)$ & & & 2.44 & $(-.31-5.19)$ & & & 2.78 & $(.98-4.57)$ & & & .18 & $(-2.10-2.45)$ & & \\
\hline Group & & & 74.73 & $<.001$ & & & 68.38 & $<.001$ & & & 1144.16 & $<.001$ & & & 42.14 & $<.001$ \\
\hline 1 & -7.85 & $(-11.70--4.00)$ & & & -7.24 & $-10.51--3.97)$ & & & -4.08 & $(-6.20--1.95)$ & & & -5.50 & $(-8.22--2.78)$ & & \\
\hline 2 & - & & & & - & & & & - & & & & - & & & \\
\hline 3 & 4.21 & $(2.29--6.13)$ & & & 1.79 & $(.16-3.42)$ & & & 1.69 & $(.63-2.75)$ & & & .18 & $(-1.18-1.54)$ & & \\
\hline Age & 5.09 & $(4.79-5.40)$ & 1072.88 & $<.001$ & 3.08 & $(2.82-3.34)$ & 543.17 & $<.001$ & 2.23 & $(2.06-2.39)$ & 672.58 & $<.001$ & .73 & $(.51-.94)$ & 43.55 & $<.001$ \\
\hline
\end{tabular}

${ }^{\mathrm{a}}$ Group 2 was set as reference.

education (Mohanty, Woolhandler, Himmelstein, Pati, Carrasquillo, Bor, 2005; Slesinger, Christenson, Cautley, 1986; Stamatakis, Wardle, Cole, 2010; Chin J School Health, 2011). Parents with high level of education have resources to promote health of children, and are in a better position to prevent or reduce their disease. Moreover, parents with high level of education may also have a higher standard of living and healthier behaviors, which have a direct influence on their children. Maternal education is shown to have a strong association with childcare and thus impacts a child's development (Boyle, Racine, Georgiades, et al., 2006; NICHD Early Child Care Research Network, 1998). Wang et al. have reported that there were strong associations between fathers' education and child development in China. (Wang \& Zhou, 2012) In this study, the education level was high in ascending order of group 1 , group 2 and group 3 in both father and mother, and children's physiques correlated with their parent's education level. This finding is consistent with previous studies (Mohanty, Woolhandler,
Himmelstein, Pati, Carrasquillo, Bor, 2005; Slesinger, Christenson, Cautley, 1986; Stamatakis, Wardle, Cole, 2010; Shi et al., 2011).

The associations between socioeconomic status and children's physiques have often been explained in terms of family income (Will, Zeeb, et al., 2005). In our study, children from high-income family have relatively bigger physique than those from low-income family (Table 6). These results are consistent with previous studies (Waterlow, Buzina, Keller, Lane, Nichaman, \& Tanner, 1977; Weinreb, Goldberg, Perloff, 1998; Wang, Zhou, 2012). The determination of how family income affects children's physique is explained in the following ways. Family income influences the ability to purchasing healthy items which have an impact on a child's growth. A poor family is much more likely to buy a large amount of cheap, unhealthy food to feed their family, rather than a small amount of nutritious food that will leave them hungry. This inadequate dietary habit results in stunting in child's growth (Casey, Szeto, Lensing, 
Bogle, \& Weber, 2001; Dittus, Hillers, \& Beerman, 1995). Furthermore, many poor families cannot purchase necessary health care services (Bradley, Kelleher, 1992; Dubay, Kenney, 2001). Family monthly income was high in ascending order of group 1, group 2 and group 3 . Therefore, similar mechanisms to previous reports are assumed to have worked on the research populations.

Then, the following results are discussed. Although there were strong associations between physiques and group, there were hardly associations between socioeconomic factors and physiques by the ANCOVA in which both socioeconomic factors and groups were taken as independent variables and age was taken as a covariate.

In this study, the education level was high in ascending order of group 1, group 2 and group 3 in both father and mother. Family monthly income was high in ascending order of group 1, group 2 and group 3. Moreover, the occupations with high wages were high in ascending order of group 1, group 2 and group 3, and on the contrary, the occupations with low wages were low in descending order of group 1, group 2 and group 3. These facts mean that the factor of group denotes the same tendency of three socioeconomic factors. This is the main reason why there were strong associations between physiques and group, but there are hardly associations between physiques and socioeconomic factors in the ANCOVA.

In addition to the socioeconomic factors, there are some other differences among the three groups such as residential area and household registration called Hukou.

While the group 1 lives in rural area, the group 2 and group 3 live in urban area. Many studies have showed that there were the differences of physiques between rural and urban areas in China (McLoyd, 1998; Zhou, 2009; Zhang \& Wang, 2006; Ma, Wu, \& Yang, 2010). Yin compared the physiques of university students between rural origin and urban origin (McLoyd, 1998). The study showed that college students whose birthplaces were in urban areas were taller and heavier than those whose birthplaces were in rural areas. The urban-origin students were still bigger than rural-origin ones after the adjustment by gross family income, family income per capita, latitude, air temperature, precipitation and altitude. It means that there are some different factors affecting physiques between rural life and urban one in childhood except for family income and other environmental factors. The results, although subjects were university students, are consistent with our findings that group 3 had bigger physiques than group 1 and group 2 after the adjustment by the family income. However, there are no previous reports that showed the difference in physiques between rural-origin children and urban-origin ones after the adjustment by parental education or occupation.

In addition to the difference of physiques between rural-origin group and urban-origin group, another important aspect of the results is that group 2 had bigger than group 1 and smaller than group 3. Yang has showed that MPWs' children have bigger physiques than rural children (Yan, 2005). Zhang reported that MPWs' children are more likely to be underweight, anemia and more likely to lack access to adequate dental care than children of citizens in Shanghai city (Zhang et al., 2005) Yin XJ showed that MPWs' children have lower weight than children of citizens in Shanghai city (Yin et al., 2011). Li $\mathrm{H}$ reported that the growth and development parameters of most children from MPWs were much lower than that of urban children (Li \& Zhou, 2011).
Although group 2 and group 3 are living in urban areas, household registration (Hukou) is different in two groups. Group 2 are entitled to none of subsidies in cities from local states due to lack of urban household registration (Solinger, 1999). Besides the issue of registration, developmental history was considered different without doubt, and perhaps lifestyle in Shanghai was also different (Ma, 2000; Wang, Shen, Liu, 2008). These factors are thought linked to the difference of physiques between the groups.

How should we substantively examine the differences of physiques between group 1 and group 2? It is clear that the migration must have effectively raised family income in group 2. In fact, the family income of group 2 was higher than group 1. However, the story is somewhat complicated, because the parental education level in group 2 was higher than group 1 . Therefore, group 2 was likely to have more income than group 1 prior to migrating. Moreover, the differences in physiques are statistically significant even after the adjustment by income. Taking these factors into consideration, the differences between group 1 and group 2 were probably caused by both the migration and original difference between them, which could not be adjusted by three socioeconomic factors.

There are some limitations in this study. First, we could not select subjects from every province where Shanghai city's MPWs came from. We selected Anhui province as a study area from following reasons: the MPWs in Shanghai city were the largest in number from Anhui province. It might have caused some selection bias in the results. Strictly speaking, the results might reflect the characteristics of Anhui province and surrounding areas. Second, although questionnaires were modified to make it easier to understand after pre-survey, a few respondents (parents or guardians) did not accurately to fill-out some parts of questionnaire. For example, some respondents did not clearly understand the classification for parental occupation, so they were not able to distinguish their particular occupation. This results in more error when comparing children's physiques by parental occupation in group 2 than in other groups. Third, there might have been some errors in physical measurement. For instance, even though children were informed to urinate and defecate before physical measurement, some children probably did not follow the guidelines we set forth in the session prior to taking their physical measurement. Finally, this was cross-sectional designed study. It is possible that there have bigger physiques in group 2 than group 1 before they came to Shanghai city from their rural area. It is difficult to infer causation for the association of children's physiques with the group.

\section{Conclusion}

In summery, we find that physiques of MPW's children were smaller than those of citizens in Shanghai City, and bigger than those of rural residents. There are strong associations between physique and socioeconomic factors. These associations also exist among children whose parents are employed in Agriculture and water conservancy labors, are unemployed or production of transport equipment operators, as they had relatively small physiques. Conversely, children whose parents had higher education had relatively bigger physiques. When family monthly income was higher, those children displayed bigger physiques in all indexes. Whereas, when both socioeconomic factors and group were taken as independent variables, in both sexes, there were strong associations between physique and 
group in all indexes, and there were hardly associations between physiques and socioeconomic factors.

\section{Acknowledgements}

The cohort study investigators from graduate School of Physical Education and Health, K University, Shanghai, China. Including: LQ Jia, B Lu, RF Wu, CC Zhang, JH Wu, Q Guo, JJ Liu.

\section{REFERENCES}

Alaimo, K., Olson, C. M., Frongillo, E. A., \& Briefel, R. R. (2001). Food insufficiency, family income, and health in US preschool and school-aged children. American Journal of Public Health, 91, 781786. http://dx.doi.org/10.2105/AJPH.91.5.781

Bogin, B., Smith, P., Orden, A. B., Varela Silva, M. I., \& Loucky, J. (2002). Rapid change in height and body proportions of Maya American children. American Journal of Human Biology, 14, 753-761. http://dx.doi.org/10.1002/ajhb.10092

Bogin, B, et al. (2002). Rapid change in height and body proportions of Maya American children. American Journal of Human Biology, 14, 753-761. http://dx.doi.org/10.1002/ajhb.10092

Belsky, J., Bell, B., Bradley, R. H., et al. (2007). Socioeconomic risk, parenting during the preschool years and child health age 6 years. European Journal of Public Health, 17, 508-513. http://dx.doi.org/10.1093/eurpub/ckl261

Black, D., Morris, J. N., Smith, C., Townsend, P., \& Whitehead, M. (1988). Inequalities in health: The Black report. London: Penguin.

Bornstein, M. H., Hahn, C. S., Suwalsky, J. T. D., \& Haynes, O. M. (2003). Socioeconomic status, parenting and child development: The Hollingshead Four-Factor Index of Social Status and the Socioeconomic Index of Occupations. Mahwah, NJ, 29-82.

Boyle, M. H., Racine, Y., Georgiades, K., et al. (2006). The influence of economic development level, household wealth and maternaleducation on child health in the developing world. Social Science \& Medicine, 63, 42-54.

Brooks-Gunn, J., \& Duncan. G. J. (1997). The effects of poverty on children. Future Child, 7, 55-71. http://dx.doi.org/10.2307/1602387

Bradley, R. H., \& Kelleher, K. J. (1992). Childhood morbidity and mortality: The growing impact of social factors. Presented at Conference Social Science Health Policy: Building Bridges between Research and Action, Washington, DC.

Chen, X. R., et al. (2010). An investigation on health condition and sports behavior of peasant workers in Pearl River Delta. China Sport Science, 30, 11-21. (Chinese)

Chen, C. M., et al. (2006). The changes of the attributable factors of child growth. Journal of Hygiene Research, 35, 765-768. (Chinese)

Chen, Q. (2001). Association of physique with environmental factors in children in Hangzhou City. Chinese Journal of School Health, 22, 339-340. (Chinese)

Chen, J. (2001). Associations of children's development with environmental factors in Hangzhou city. Chinese Journal of School Health, 22, 339-340. (Chinese)

Casey, P. H., Szeto, K., Lensing, S., Bogle, M., \& Weber, J. (2001). Children in food insufficient low-income families: prevalence, health and nutrition status. Archives of Pediatrics \& Adolescent Medicine, 155, 508-514. http://dx.doi.org/10.1001/archpedi.155.4.508

Desai, S., \& Alva, S. (1998). Maternal education and child health: Is there a strong causal relationship? Demography, 35, 71-81. http://dx.doi.org/10.2307/3004028

Dittus, K. L., Hillers, V. N., \& Beerman, K. A. (1995). Benefits and barriers to fruit and vegetable intake: relationship between attitudes and consumption. Journal of Nutrition Education, 27, 120-126. http://dx.doi.org/10.1016/S0022-3182(12)80802-8

Dubay, L, \& Kenney, G. (2001). Health care access and use among low-income children: Who fairs best. Health Affairs, 20, 112-121. http://dx.doi.org/10.1377/hlthaff.20.1.112

Frisancho, A R. (1981). New norms of upper limb fat and muscle areas for the assessment of nutritional status. American Journal of Clinical Nutrition, 34, 2540-2545.

Fredriks, A. M., Buuren, S., Jeurissen, S. E. R., et al. (2004). Height, weight, body mass index and pubertal development references for children of Moroccan origin in The Netherlands. Acta Paediatrica, 93, 817-824.

Geltman, P. L., Radin, M., Zhang, Z., Cochran, J., \& Meyers, A. F. (2001). Growth status and related medical conditions among refugee children in Massachusetts. American Journal of Public Health, 191, 1800-1805.http://dx.doi.org/10.2105/AJPH.91.11.1800

Guarnaccia, P., \& Lopez, S. (1998). Mental health and adjustment of immigrant and refugee children. Child Adolescent Psychiatric Clinics of North America, 7, 537-553.

Glew, R. H., Brock, H. S., et al. (2004). Lung function and nutritional status of semi-nomadic Fulani children and adolescents in Northern Nigeria. Journal of Tropical Pediatrics, 50, 20-25. http://dx.doi.org/10.1093/tropej/50.1.20

Garnier, D., Ndiaye, G., \& Benefice, E. (2003). Influence of urban migration on physical activity, nutritional status and growth of Senegalese adolescents of rural origin. Bulletin de la Société de Pathologie Exotique, 96, 223-227.

Hu, X P. (2004). Going out for a non-farming job: An effective way to increase farmers' income. Issues in Agricultural Economy, 24, 63-66. (Chinese)

http://www.stats.gov.cn/tifx/jdfx/t20120120_402780174.htm

Hernandez, D. J. (2004). Demographic change and the life circumstances of immigrant families. Future Child, 14, 17-45. http://dx.doi.org/10.2307/1602792

Huang, Z. J., Stella, M. Y., et al. (2006). Health status and health service access and use among children in US immigrant families. American Journal of Public Health, 96, 634-640. http://dx.doi.org/10.2105/AJPH.2004.049791

http://www.stats.gov.cn/tjfx/jdfx/t20110428_402722253.htm

http://en.wikipedia.org/wiki/Anhui

http://en.wikipedia.org/wiki/Shanghai

http://www.moh.gov.cn/publicfiles/business/htmlfiles/wsb/pzcjd/20080 4/21290.htm

http://www.cdc.gov/nchs/nhis/quest data related 1997 forward.htm\#2 012 NHIS

http://www.maine.gov/education/sh/heightandweight/heightweight.pdf.

Halldorsson, M., Kunst, A., Kohler, L., \& Mackenbach, J. P. (2000). Socio-economic inequalities in the health of children and adolescents - A comparative study of the five Nordic countries. European Journal of Public Health, 10, 281-288. http://dx.doi.org/10.1093/eurpub/10.4.281

Hervey, K., Vargas, D., Klesges, L., Fischer, P. R., Trippel, S., \& Juhn, Y. J. (2009). Overweight among refugee children after arrival in the United States. Journal of Health Care for the Poor and Underserved, 20, 246-256. http://dx.doi.org/10.1353/hpu.0.0118

Kuh, D. L., Power, C., \& Rodgers, B. (1991). Secular trends in social class and sex differences in adult height. International Journal of Epidemiology, 20, 1001-1009. http://dx.doi.org/10.1093/ije/20.4.1001

$\mathrm{Li}$, H., \& Zhou, B. S. (2011). The cross-sectional investigation on growth and development of children aged eight to eleven from migrant workers' family in Shenyang City. Journal of China Medical University, 40, 1049-1051.

Ma, C. J. (2008). Analysis of influencing factors and physical health condition of migrant peasant workers in Henan province. Journal of Anhui Agriculture Science, 36, 4719-4720.

Mirza, N. M., Kadow, K., Palmer, M., Solano, H., Rosche, C., \& Yanovski, J. A. (2004). Prevalence of overweight among inner city Hispanic-American children and adolescents. Obesity Resarch, 12, 12981310 .

Morton, B., Hou, F., Hyman, I., \& Tousignant, M. (2002). Poverty, family process and the mental health of immigrant children in Canada. American Journal of Public Health, 92, 220-227. http://dx.doi.org/10.2105/AJPH.92.2.220

McBride, B. A. (1990). The effects of a parent education/play group program on father involvement in child rearing. Family Relations, 39, 250-256. http://dx.doi.org/10.2307/584868 
Mahoney, G., Kaiser, A., Girolametto, L., MacDonald, J., Robinson, C., Safford, P., \& Spiker, D. (1999). Parent education in early intervention: A call for a renewed focus. Topics in Early Childhood Special Education, 19, 131-140. http://dx.doi.org/10.1177/027112149901900301

McLoyd, V. C. (1998). Socioeconomic disadvantage and child development. American Psychologist, 53, 185-204. http://dx.doi.org/10.1037/0003-066X.53.2.185

Ma, S., Wu, S. X., \& Yang, Z. (2010). Analysis of growth and development of urban and rural students in Beijing. Chinese Journal of School Health, 32, 1296-1299.

Ma, D. F. (2000). Marginalized migrant peasant worker in cities. Youth Studies, 29, 19-22.

NICHD Early Child Care Research Network. (1998). Relations between family predictors and child outcomes: Are they weaker for children in child care? Developmental Psychology, 34, 1119-1128. http://dx.doi.org/10.1037/0012-1649.34.5.1119

Ortega, A., Fang, H., Perez, V. H., Rizzo, J. A., Carter-Pokras, O., Wallace, S. P., \& Gelberg, L. (2007). Health care access, use of services and experiences among undocumented Mexicans and other Latinos. JAMA Internal Medicine, 167, 2354-2360. http://dx.doi.org/10.1001/archinte.167.21.2354

Parke, R. D., Coltrane, S., Duffy, S., Buriel, R., Dennis, J., Powers, J., French, S., \& Widaman, K. F. (2004). Economic stress, parenting, and child adjustment in Mexican American and European American families. Child Development, 75, 1632-1656. http://dx.doi.org/10.1111/j.1467-8624.2004.00807.x

Rona, R. J., \& Chinn, S. (1991). Father's unemployment and height of primary school children in Britain. Annals of Human Biology, 18, 441-448. http://dx.doi.org/10.1080/03014469100001742

Solinger, D. (1999). Contesting citizenship in urban China. Peasant migrants, the state, and the logic of the market. Berkeley, CA: University of California press.

Mohanty, S. A., Woolhandler, S., Himmelstein, D. U., Pati, S., Carrasquillo, O., \& Bor, D. H. (2005). Health care expenditures of immigrants in the United States: A nationally repre-sentative analysis. American Journal of Public Health, 95, 1431-1438. http://dx.doi.org/10.2105/AJPH.2004.044602

Slesinger, D. P., Christenson, B. A., \& Cautley, E. (1986). Health and mortality of migrant farm children. Social Science \& Medicine, 23, 65-74. http://dx.doi.org/10.1016/0277-9536(86)90325-4

Stamatakis, E., Wardle, J., \& Cole, T. J. (2010). Childhood obesity and overweight prevalence trends in England: Evidence for growing socioeconomic disparities. International Journal of Obesity, 34, 41-47. http://dx.doi.org/10.1038/ijo.2009.217

Shi, J. X. et al. (2011). Analysis on physique among aged 3 to 6 year old childrenin Xiamen City. Chinese Journal of School Health, 32, 1378-1379.

State Statistic Bureau. (2010). The Monitoring Survey Report of Migrant Peasant Workers in 2009. Beijing: State Statistic Bureau.
Thomas, D., Strauss, J., \& Henriques, M. H. (1991). How does mother's education affect child height. The Journal of Human Resources, 26, 183-211. http://dx.doi.org/10.2307/145920

uxin, et al. (2007). Analysis and forecast on China's social development. Beijing: Social Sciences Academic Press.

Will, B., Zeeb, H., \& Baune, B. T. (2005). Overweight and obesity at school entry among migrant and German children: A cross-sectional study. BMC Public Health, 5, 45.

http://dx.doi.org/10.1186/1471-2458-5-45

Waterlow, J. C., Buzina, R., Keller, W., Lane, J. M., Nichaman, M. Z., \& Tanner, J. M. (1977). The presentation and use of height and weight data for comparing the nutritional status of groups of children under the age of 10 years. Bulletin of the World Health Organization, $55,489-498$.

Weinreb, L., Goldberg, R., \& Perloff, J. (1998). Health characteristics and medical services patterns of sheltered homeless and low income housed mothers. Journal of General Internal Medicine, 13, 389-397. http://dx.doi.org/10.1046/j.1525-1497.1998.00119.x

Wang, F., \& Zhou, X. (2012). Family—Related factors affecting child health in China. Population Research, 36, 50-59.

Wang, G. X., Shen, J. F., \& Liu, J. B. (2008). Citizenization of peasant migrants during urbanization in China-A case study of Shanghai. Population \& Development, 15, 70-95.

Xiong, Y. H. (2010). Bottom layer, the school and class reproduction. Open Times, 29, 94-110.

Yan, Z. (2005). Comparison of health and behavior in migrant peasant worker's children. Hangzhou: Zhejiang University.

Yin, X. J. et al. (2011). Comparative study of physical fitness between migrant workers' school children and those of the Shanghai natives. Journal of Chengdu Sport University, 37, 66-69.

Yu, S. M., Huang, Z. J., \& Singh, G. K. (2004). Health status and health services utilization among US Chinese, Asian Indian, Filipino, and other Asian/Pacific Islander children. Pediatrics, 113, 101-107. http://dx.doi.org/10.1542/peds.113.1.101

Yin, X. J., Huang, C. Q., Chen, H. M., \& Tanaka, T. (2005). Associations of physique with socioeconomic factors of family and regional origin in Chinese university students. Environmental Health and Preventive Medicine, 10, 190-200. http://dx.doi.org/10.1007/BF02897710

Zhang, Z. S. et al. (2005). The health status and common disease among migrant peasant worker's children in primary school of Chang Nin district in Shanghai. Shanghai Journal of Prevention Medicine, 17, 70-71.

Zhou, G. M. (2009). A comparative study on the physiques of children in rural and urban Guiyang. Journal of Gui Zhou University for Ethnic Minorities (Philosophy and Social Sciences), 29, 157-159.

Zhang, Y. M., \& Wang, Z. (2006). Investigation of constitution state of three- to six-year-old children in urban and rural areas of Wei Fang city. Chinese Journal of Tissue Engineering Research, 10, 13-15. 